EJMBE

31,2

192

Received 27 May 2021

Revised 22 July 2021

7 August 2021

Accepted 9 August 2021

\section{Change tolerance, group focus and students' entrepreneurial intentions: does gender matter?}

\author{
Gloria Haddad \\ Management, Faculty of Business and Management, \\ Saint Joseph University of Beirut, Beirut, Lebanon \\ Ghada Haddad \\ Leadership and Organizational Behavior, ESC Pau Business School, \\ Pau, France, and \\ Gautam Nagpal \\ Management, ESC Pau Business School, Pau, \\ France and Université de Pau et des Pays de l'Adour, \\ E2S UPPA, CNRS, TREE, Pau, France
}

\begin{abstract}
Purpose - This study examines the impact of cultural dimensions on entrepreneurial intentions (EIs) and the mediating role of planned behavior (TPB) determinants between change tolerance (CT), group focus (GF), and EIs for both men and women in the context of international business schools.

Design/methodology/approach - Using a quantitative research design, data were collected in France through anonymous questionnaires. The data consisted of responses from 480 business students. Structural equation modeling (SEM) and the bootstrap method with PROCESS macro were used to determine the significance of the mediation effects.

Findings - Results reveal the strong impact of CT on the EIs of both men and women through TPB antecedents. They also indicate that GF has an indirect effect on EIs through TPB antecedents for men and an indirect multiple mediation effect on EIs through CT and TPB antecedents for both men and women.

Originality/value - The extended TPB model is original in that it supports both the determinants of planned behavior and cultural dimensions and provides a valuable perspective through its findings on cultural and gender diversity in entrepreneurship.
\end{abstract}

Keywords Change tolerance, Group focus, Entrepreneurial intentions, Gender differences,

Cultural dimensions, Business schools

Paper type Research paper

\section{Introduction}

As entrepreneurship plays an important role in stimulating economic growth, it continues to attract the attention of scholars who attempt to understand its processes and the social factors that lead to its development across different countries (Doran et al., 2018; Lu et al., 2021; Rico and Cabrer-Borrás, 2019; Seyoum et al., 2021). This is particularly true for Europe, which suffers from gender imbalance in entrepreneurship due to socio-cultural barriers that have traditionally put women at a structural disadvantage, leading to missed opportunities, both socially and economically (World Economic Forum, 2020).

(C) Gloria Haddad, Ghada Haddad and Gautam Nagpal. Published in European Journal of Management and Business Economics. This article is published under the Creative Commons Attribution (CC BY 4.0) licence. Anyone may reproduce, distribute, translate and create derivative works of this article (for both commercial and non-commercial purposes), subject to full attribution to the original publication and authors. The full terms of this licence maybe seen at http://creativecommons.org/licences/by/4.0/ legalcode 
Previous studies have focused on entrepreneurial intentions (EIs) as they help predict future entrepreneurial actions (Bogatyreva et al., 2019; Krueger et al., 2000; Liñán and Chen, 2009; Nowiński and Haddoud, 2019; Seyoum et al., 2021). Research on gender differences in entrepreneurial intentions revealed that men have stronger EIs than women (Díaz-García and Jiménez-Moreno, 2010; Santos et al., 2016; Sweida and Sherman, 2020; Yukongdi and Lopa, 2017). However, more empirical evidence is needed to explain such variations (Choukir et al., 2019; Elnadi and Gheith, 2021; Gurel et al., 2021; Shinnar et al., 2012). Some scholars argue that differences may exist due to contextual influences that affect the perceptions of men and women (Byrne and Fayolle, 2010; Moriano et al., 2012; Haddad et al., 2016, 2021; Haddad, 2017); hence, many studies have attempted to combine gender with culture to investigate EIs across different nations and cultures (Liñán and Chen, 2009; Shinnar et al., 2012, 2018). Unique cultural contexts may indeed present opportunities and challenges for driving entrepreneurship (Elnadi and Gheith, 2021; Gurel et al., 2021; Krueger et al., 2013). However, macro-level studies neglect within-group differences and the fact that members of a particular nation may vary in the extent to which they relate or adhere to prevailing cultural norms and values (Kirkley, 2016; Pruett et al., 2009).

To examine how change tolerance (CT) and group focus (GF) affect the EIs of 480 students in French international business schools, this study leans on the theory of planned behavior (TPB) (Ajzen, 1991), which is widely applied in entrepreneurship research to investigate intentions (Lortie and Castogiovanni, 2015) and individual cultural dimensions (Solomon and Schell, 2009). This study addresses a gap in current knowledge regarding the way in which individual cultural values affect EIs across genders. Reliance on a student sample is quite common when examining intentions (Liñán and Chen, 2009; Shinnar et al., 2012; Choukir et al., 2019; Haddad et al.,2021) because students need to make immediate career choices and starting a new venture may be a realistic option for them (Krueger et al., 2000). Choosing international business schools in France as the context for this research stems from the fact that the country is supportive of entrepreneurship and highly responsive to the needs of business creators. Furthermore, multinational schools are a typical environment for studies dealing with cultural diversity.

The rest of this paper is organized as follows. Section 2 outlines the theoretical framework and the research hypotheses that derived from it. Section 3 provides a full description of the methods and instruments used. The findings of the statistical analyses are reported in Section 4. A discussion is detailed in Section 5. Finally, concluding remarks regarding the implications of the study and future research avenues are outlined in Section 6.

\section{Theoretical framework \\ Entrepreneurial intentions}

Several scholars have stated that EIs and cognitive structures are essential for understanding entrepreneurship (Krueger et al., 2000; Krueger, 2017; Liñán and Chen, 2009). As it is an immediate antecedent of behavior, a significant body of research uses intention models and focuses on intention (Ajzen, 1991). One of the most widely used models to explore the direct and indirect antecedents of intentions is the TPB (Ajzen, 1991). The TPB model includes three motivational factors that affect EIs. The first is the personal attitude toward entrepreneurship, which refers to the extent to which a person has a positive or negative assessment of entrepreneurship. The second is subjective norms and refers to the role of significant others (e.g. family, relatives and friends) in approving or disapproving of entrepreneurial behavior. The third is perceived behavioral control, which refers to the perception of difficulty or ease to undergo the entrepreneurial process (García-Rodríguez et al., 2015). Perceived behavioral control is a proxy of the self-efficacy concept coined by Bandura (1977), which refers to the self-perception of the capacity to perform a certain action, such as establishing a new business (Krueger et al., 2000). Lortie and Castogiovanni (2015) demonstrate the robustness of the TPB model in entrepreneurship research and its
Culture and theory of planned behavior 
EJMBE 31,2

194 capacity to explain EIs. The overall conceptual model that illustrates the relationships between TPB constructs, EIs and cultural influences on entrepreneurship is illustrated in Figure 1.

\section{Gender and entrepreneurial intentions}

Previous studies suggest that men exhibit stronger EIs than women (Díaz-García and JiménezMoreno, 2010; Sweida and Sherman, 2020; Yordanova and Tarrazon, 2010; Yukongdi and Lopa, 2017). Gender differences exist because of the manner in which self-beliefs and attitudes toward entrepreneurship are developed. Previous research indicates that women tend to perceive lower opportunities and higher barriers to entrepreneurship than their male counterparts (Santos et al., 2016). These variations can be explained by the dissimilar effect of contextual influences on the perceptions of men and women (Byrne and Fayolle, 2010; Elnadi and Gheith, 2021; Haddad and Loarne, 2015), the roles they are attributed in society (Haddad, 2017), and the type of education they receive (Haddad et al, 2016; Gurel et al, 2021; Boubker et al., 2021; Lu et al, 2021). Díaz-García and Jiménez-Moreno (2010) demonstrate that subjective norms related to entrepreneurship can greatly affect the EIs of women because they are highly conditioned by societal values and the roles ascribed to them. They generally believe that they are less qualified than men for entrepreneurial work (Stedham and Wieland, 2017). The low self-efficacy they have compared to men affects their EIs and their propensity to follow an entrepreneurial career (Haddad et al, 2016; Santos et al, 2016). However, the effect of high self-efficacy on intentions is stronger for women (Kickul et al, 2008). Despite numerous studies that acknowledge differences between men and women in terms of EIs, some scholars argue that empirical evidence is still insufficient to explain such variations (Shinnar et al, 2012, 2018). Based on previous findings regarding gender and EIs, this study posits the following hypotheses:

H1a. Gender differences exist in entrepreneurial intentions, such that the effect of personal attitude toward entrepreneurship on intentions is stronger for men.

H1b. Gender differences exist in entrepreneurial intentions, such that the effect of subjective norms on intentions is stronger for women.

H1c. Gender differences exist in entrepreneurial intentions, such that the effect of perceived behavioral control on intentions is stronger for women.

\section{Cultural influences on entrepreneurship}

Morris et al. (1994, p. 70) define culture as a "learned, socially transmitted set of behavior standards." It is the "collective programming of the mind that distinguishes the members of

Figure 1.

Conceptual model

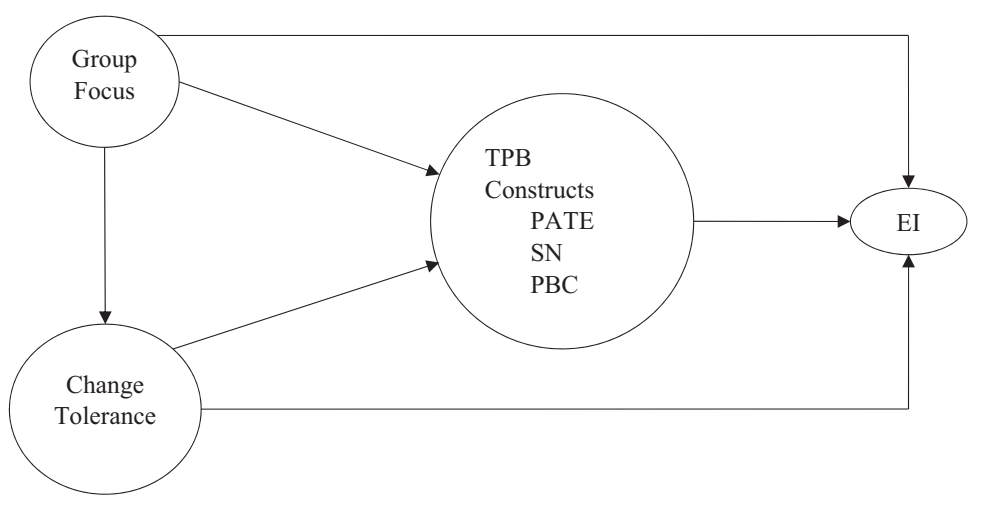


one human group from another" and comprises systems and values (Hofstede, 1980, p. 25). They influence the extent to which people and societies consider entrepreneurial behaviors as desirable (Watson et al., 2019). National culture is often seen as central to the entrepreneurship field. Among its different conceptualizations, Hofstede's (1980) dimensions are the most widely used in entrepreneurship and management studies (Watson et al., 2019). Unique cultural, national, and institutional contexts present opportunities and challenges for driving entrepreneurship (Krueger et al., 2013). Previous research acknowledges the impact of culture on EIs using national cultural dimensions. However, these studies neglect within-group differences and the fact that members of a particular nation may vary in the extent to which they relate or adhere to prevailing cultural norms and values (Kirkley, 2016; Pruett et al., 2009). The current study focuses on two individual cultural dimensions, CT and GF, to investigate their direct and indirect effects on EIs.

\section{Change tolerance}

Change tolerance refers to the comfort level with novelty, risk taking and change (Solomon and Schell, 2009). Highly change-tolerant people take risks and view transformation as a natural part of their lives. They are creative, flexible and receptive to innovative ideas and do not fear failure to undertake new ventures (Solomon and Schell, 2009). Hofstede (2001) demonstrated that people who accept uncertainty are more at ease with new situations, which leads them to launch new businesses. Other research linked tolerance to change with innovation, thus explaining that change-tolerant people are more prone to developing innovative ways of doing things (Mueller and Thomas, 2001; Shane, 1993) and take advantage of opportunities they identify in their surroundings (Busenitz, et al., 2000). Numerous studies support the fact that societies that encourage risk taking and acknowledge uncertainty tend to have more entrepreneurial members (Kreiser, et al., 2010; McGrath et al., 1992; Mueller and Thomas, 2001). Moreover, it has also been revealed that there is a strong relationship between risk tolerance and self-efficacy (Serino and Buccino, 2019) and between high-risk preference and EIs (Gurel et al., 2021; Nasip et al., 2017). Regarding gender differences in relation to risk taking, the literature indicates that women are more risk-averse than men, which negatively influences their propensity to step into entrepreneurship (Shinnar et al., 2012, 2018). Despite this, women in some contexts, such as Sub-Saharan societies, may seek entrepreneurship to achieve higher social positions (Anlesinya, 2019).

Based on the theory that CT is associated with high comfort when dealing with risk, novelty, and change, that risk taking is associated with entrepreneurship attitude and selfefficacy, and that men are more risk tolerant than women, this study formulates the following hypotheses:

$H 2 a$. Gender differences exist in entrepreneurial intentions, such that the direct effects of change tolerance on intentions is stronger for men.

$H 2 b$. Gender differences exist in entrepreneurial intentions, such that the indirect effects of change tolerance on entrepreneurial intentions, through TPB antecedents, is stronger for men.

\section{Group focus}

As defined by Solomon and Schell (2009) at the individual level, GF could be matched with Hofstede's (1980) cultural dimension of collectivism. People in group cultures always seek consensus in decisions and seldom take the initiative or implement changes without discussing it with the group. They are motivated by greater security and affiliation opportunities (Solomon and Schell, 2009). Bullough et al. (2017) divided collectivism into two categories: institutional and in-group collectivism. Institutional or societal collectivism reflects the degree to which society,
Culture and theory of planned behavior 
EJMBE 31,2 such as laws, social programs and institutions, values group fidelity and unity over individual accomplishments. On the other hand, in-group collectivism reveals the extent to which people express dignity, trustworthiness, and solidarity in their families and how much they depend on them (Bullough et al., 2017). In contrast, people in individualistic cultures focus on personal achievement and feel responsible for their own actions (Hofstede, 1980). They are motivated by the recognition of their talents and achievements and have the capacity to evaluate risk and make quick decisions (Solomon and Schell, 2009). Several empirical studies have revealed the positive influence of individualistic cultures on entrepreneurship since they accentuate the identity of an individual more than their society, which increases self-confidence, initiative and courage to take risks (Hayton et al., 2002; Mueller and Thomas, 2001; Rantanen and Toikko, 2017). Some previous works conceptualized collectivism and individualism as two opposing dimensions, while others suggested that they constitute two different attributes at the individual level, implying that a person can have both tendencies depending on the different situations they encounter (Farrukh et al., 2019; Rantanen and Toikko, 2017). Thus, individualism and collectivism do not imply two ends of the same scale (Oyserman, 2006). People may hold both an autonomous and a reliant sense of self, and each of these two dimensions may prevail across different circumstances (Markus and Kitayama, 1991). Rantanen and Toikko (2017) found that collectivism and individualism are significant factors in determining EIs. On the one hand, because individualist values such as individual autonomy and competitiveness promote entrepreneurial intentions, and on the other, because communality creates a socio-cultural capital that positively impacts EIs. Collective practices are then significant for entrepreneurial development because working in teams is an opportunity to solve problems and find and implement innovative ideas (Anlesinya, 2019; Lechler, 2001). The controversial findings regarding collectivist values and entrepreneurship in studies that applied the TPB model call for a deeper understanding of the impact of GF. While supporting the evidence that no gender differences exist in relation to the individualism/collectivism dimension (Hofstede, 2001; Shinnar et al., 2012), we formulate the following hypotheses:

H3a. Group focus has a direct positive and significant impact on entrepreneurial intentions.

H3b. Group focus has an indirect positive and significant impact on entrepreneurial intentions through TPB antecedents.

Individuals driven by a GF mindset are more inclined to meet others' expectations and sustain social harmony (Solomon and Schell, 2009); they seek motivation and support from others to take entrepreneurial risks and create new ventures (Anlesinya, 2019; Lechler, 2001; Rantanen and Toikko, 2017). Further, the knowledge that a learner acquires through formal and informal activities in educational environments alters their perceptions and attitudes, thus producing behavioral changes such as the willingness to undergo new experiences, develop new ideas and skills, and try new things (Matthews et al., 2020). A gender comparative study indicates that interactions with people help individuals, particularly women, to develop their entrepreneurial opportunities and boost their self-confidence to take risks and engage in the entrepreneurial process (Haddad and Loarne, 2015). Nevertheless, the theoretical evidence that group interactions can reduce risk aversion remains scarce. This study provides empirical proof on the mediation effect of CT between GF and EIs. Consequently, the following hypotheses are formulated:

$H 4 a$. Change tolerance mediates the relationship between group focus and entrepreneurial intentions.

$H 4 b$. Change tolerance and TPB antecedents mediate the relationship between group focus and entrepreneurial intentions. 


\section{Methodology}

This study examines the relationships between CT, GF, TPB constructs and students' EIs. A questionnaire survey was administered to 480 students, all pursuing degrees in business administration. This method of convenience sampling is extensively used in entrepreneurship research (de Jorge et al., 2012; Karimi et al., 2013, 2014; Liñán et al., 2011). The questionnaire was subsequently administered to students in an electronic form using the data collection tool Sphinx. Overall, 425 responses were received, and after data cleaning and screening for missing data and outliers (Hair et al., 2014), 407 valid questionnaires were obtained, with an effective response rate of $84.79 \%$. A total of $47.9 \%$ of the respondents reported being male, while $52.1 \%$ of respondents were female. Overall, $76 \%$ of them were aged 18-25 years, while $23.6 \%$ were over 25 years of age. In terms of education level, $34.4 \%$ were undergraduates, $40 \%$ graduates and $25.6 \%$ had completed a post-graduate course.

\section{Measurement}

The survey instrument included measurement scales used in other research and was assessed using self-report measures based on multi-item scales.

\section{Entrepreneurial intentions (EIs)}

To assess entrepreneurial intentions, we used the scale used in earlier studies (Liñán et al., 2011; Liñán and Chen, 2009). The construct consisted of four items measured on a seven-point Likert scale $(1=$ total disagreement to $7=$ total agreement with each statement). A singleoverall sub-scale was used to measure the following intentions: ready to do anything to be an entrepreneur, professional goal to be an entrepreneur, making every effort to start and run a firm, and determined to create a firm. Confirmatory factor analysis (CFA) suggested a single dimension of entrepreneurial intentions with an acceptable critical ratio for the items 0.76 , average variance extracted of 0.65 , and Cronbach's alpha reliability of 0.86 . The average score of the six items was calculated and labeled EI.

\section{TPB constructs}

We assessed the TPB constructs, that is, personal attitude toward entrepreneurship (PATE), subjective norms (SN) and perceived behavioral control (PBC) using a similar scale to that used by earlier research (Liñán et al., 2011; Liñán and Chen, 2009). PATE was measured as being an entrepreneur is advantageous, career as an entrepreneur is attractive, willingness to start given the resources, and being an entrepreneur would entail great satisfaction. The measures of SN were approval of the decision to create a firm by close family, friends, or colleagues. PBC was assessed using knowledge of necessary practical details to start a firm, knowing how to develop an entrepreneurial project, and having a high probability of success. For all TPB constructs, we employed a seven-point Likert scale to measure responses $(1=$ total disagreement to $7=$ total agreement with each statement). CFA suggests that all three constructs of TPB are supported, and reliability testing also found strong support for $\operatorname{PATE}(\mathrm{CR}=0.82 ; \mathrm{AVE}=0.74$ and $\alpha=0.90)$, $\mathrm{SN}(\mathrm{CR}=0.81 ; \mathrm{AVE}=0.83$, and $\alpha=0.93)$, and $\mathrm{PBC}(\mathrm{CR}=0.62 ; \mathrm{AVE}=0.59$ and $\alpha=0.74)$. The three TPB constructs were labeled PATE, $S N$ and $P B C$, respectively.

\section{Cultural variables}

The cultural variables change tolerance (CT) and group focus (GF) have been introduced to the TPB model for the first time through this study. Following Solomon and Schell (2009), we measured CT using change generally improves process, people should be encouraged to take prudent risks, comfortable introducing changes in life, and positive spin on new
Culture and theory of planned behavior 
EJMBE 31,2 ideas proposed. GF was measured by solving challenges in groups, team members clearing their work with each other, recognition as part of a team, and comfortable presenting business plan in a team. Measurement was performed using a five-point Likert scale (one $=$ total disagreement to five $=$ total agreement with each statement) for both CT and group focus.

\section{8}

\section{Results}

Measurement model

As outlined by Anderson and Gerbing (1988), a CFA model was employed to assess the overall fit of the measurement model. The results are presented in Table 1. Overall, we found strong support for the measures with acceptable standardized loading for all items as well as critical ratios above the threshold of 2.0. We examined the scale items, factor

\begin{tabular}{lcc}
\hline Scales & Standardized & Critical \\
loading & ratio \\
\hline
\end{tabular}

EIs (Entrepreneurial intentions) (seven-point Likert-type scale: 1 representing strong disagreement to 7 representing strong agreement)

1. I am ready to do anything to be an entrepreneur $\quad 0.74 \quad 14.1$

$\begin{array}{lll}\text { 2. My professional goal to become an entrepreneur } & 0.85 & 16.0\end{array}$

3. I will make every effort to start and run my own firm $\quad 0.80 \quad 15.1$

$\begin{array}{lll}\text { 4. I have thought very seriously about starting a firm } & 0.72 & 14.1\end{array}$

PATE (Personal attitude toward Entrepreneurship) (seven-point Likert-type scale: 1 representing strong disagreement to 7 representing strong agreement)

$\begin{array}{lll}\text { 1. Being an entrepreneur implies more advantages than disadvantages } & 0.73 & 17.7\end{array}$ to me

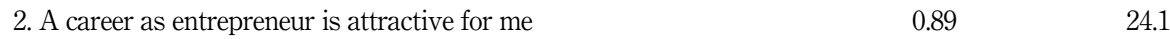

3. If I had the opportunity and resources, I'd like to start a firm $\quad 0.86 \quad 24.1$

4. Being an entrepreneur would entail great satisfaction for me $\quad 0.86 \quad 23.7$

SN (subject norm) (If you decide to create a firm, would people in your close environment approve of that decision?)

$\begin{array}{lll}1 \text {. Your close family } & 0.87 & 26.2\end{array}$

$\begin{array}{lll}\text { 2. Your friends } & 0.87 & 32.2\end{array}$

3. Your colleagues $\quad 0.89 \quad 31.5$

PBC (Perceived behavioral control) (seven-point Likert-type scale: 1 representing strong disagreement to 7 representing strong agreement)

$\begin{array}{lll}\text { 1. I know the necessary practical details to start a firm } & 0.58 & 36.8\end{array}$

2. I know how to develop an entrepreneurial project $\quad 0.99 \quad 36.8$

3. If I tried to start a firm, I would have a high probability of succeeding $\quad 0.63 \quad 33.2$

CT (change tolerance) (five-point Likert-type scale: 1 representing strong disagreement to 5 representing strong agreement)

1. I think that change generally improves process $\quad 0.65 \quad 10.7$

2. I believe that people should be encouraged to take prudent risks $\quad 0.69 \quad 11.2$

3. I am comfortable introducing changes into my daily life $\quad 0.65 \quad 10.5$

4. When proposing new ideas, I like to put a positive spin on them $\quad 0.70 \quad 10.7$

Table 1.

Confirmatory factor analysis (CFA) of items and measurement properties of the scales

GF (group focus) (five-point Likert-type scale: 1 representing strong disagreement to 5 representing strong agreement)

1. When confronted with a challenge, I prefer to solve it with a group $\quad 0.62 \quad 9.0$

2. I believe that team members should clear their work with each other $\quad 0.65 \quad 9.0$

3. I prefer to be recognized as part of a team (rather than alone) $\quad 0.60 \quad 8.6$

4. I am most comfortable presenting a business plan as part of a team $\quad 0.58 \quad 8.4$ 
loadings, reliability and fit statistics and found them all to be in the acceptable range. This suggests that the standardized loadings significant for the items and the constructs are acceptable. Convergent validity can be determined when the item coefficients of the latent construct are significant. Anderson and Gerbing (1988) suggest that when the corresponding $t$-values (critical ratios) are greater than 2.0, there is evidence of convergent validity. CFA was also achieved by observing that each item loaded significantly on the factor. The fit indices suggest that the model fits the data very well $\left(\chi^{2} / \mathrm{df}=1.605, \mathrm{RMSEA}=0.039, \mathrm{TLI}=0.970, \mathrm{CFI}=0.974, \mathrm{GFI}=0.935\right)$. These approaches confirmed the discriminant and convergent validity of the constructs in the model (Anderson and Gerbing, 1988; Fornell and Larcker, 1981). The construct values, Cronbach's alphas, critical ratio and average variances extracted for each construct are reported in Table 2.

The correlations for the constructs used in this analysis are presented in Table 3. These findings provide further evidence for the discriminant validity of the measures employed herein.

\section{Research model results}

Following CFA, the structural model was examined using IBM-AMOS to validate the hypothesized model. We use a two-step analysis process following Anderson and Gerbing (1988). The first step involved a multistage process to validate the overall construct validity of the measures used in this study. The second step employed SEM to test our hypotheses simultaneously and the mediating effects of change tolerance and the TPB constructs on EIs. Following Anderson and Gerbing (1988), the error variances of the composite scores were used for the latent variables. The results of the final structural model, along with the standardized coefficients of each hypothesized path and the model fit indices, are reported in Table 4.

This study employed the bootstrapping technique. Data were bootstrapped with 5,000 samples to explain the relationships between cultural influences on TPB and EI. The overall hypothesized model is illustrated in Figure 2.

\begin{tabular}{|c|c|c|c|c|}
\hline Construct & Cronbach's alpha & $\mathrm{CR}$ & AVE & \\
\hline EIs & 0.86 & 0.72 & 0.61 & \\
\hline PATE & 0.90 & 0.78 & 0.70 & \\
\hline SN & 0.93 & 0.78 & 0.80 & \\
\hline $\mathrm{PBC}$ & 0.95 & 0.59 & 0.57 & \\
\hline CT & 0.77 & 0.80 & 0.45 & Table 2. \\
\hline GF & 0.71 & 0.70 & 0.38 & Summary of constructs \\
\hline
\end{tabular}

\begin{tabular}{|c|c|c|c|c|c|c|}
\hline & 1 & 2 & 3 & 4 & 5 & \\
\hline \multicolumn{7}{|l|}{$1 \mathrm{EIs}$} \\
\hline 2 PATE & $0.58^{* * *}$ & & & & & \\
\hline $3 \mathrm{SN}$ & $0.61^{* * *}$ & $0.71^{* * *}$ & & & & \\
\hline $4 \mathrm{PBC}$ & $0.61^{* *}$ & $0.72^{* * *}$ & $0.88^{* *}$ & & & \\
\hline $5 \mathrm{CT}$ & $0.27^{* *}$ & $0.36^{* * *}$ & $0.22^{* * *}$ & $0.23^{* * *}$ & & \\
\hline $6 \mathrm{GF}$ & 0.03 & $0.23^{* *}$ & 0.10 & $0.11^{*}$ & $0.40^{* *}$ & Correlations of \\
\hline \multicolumn{6}{|c|}{ Note(s): $* * p<0.01, * p<0.05$} & constructs \\
\hline
\end{tabular}




\section{EJMBE 31,2}

\begin{tabular}{lc}
\hline Hypotheses & Relationships \\
\hline Theory of planned behavior \\
H1a & PATE $\rightarrow$ EIs \\
H1b & SN $\rightarrow$ EIs \\
H1c & PBC $\rightarrow$ EIs
\end{tabular}

\section{0}

Cultural influences

$\begin{array}{ll}H 2 a & \text { CT } \rightarrow \text { EIs } \\ H 2 b & \text { CT } \rightarrow \text { PATE } \\ H 2 b & \text { CT } \rightarrow \text { SN } \\ H 2 b & \text { CT } \rightarrow \text { PBC } \\ H 3 a & \text { GF } \rightarrow \text { EIs } \\ - & \text { GF } \rightarrow \text { PATE } \\ - & \text { GF } \rightarrow \text { SN } \\ - & \text { GF } \rightarrow \text { PBC }\end{array}$

Chi-square

df

Adjusted Chi-square

$p$

RMR

GFI

TLI

Table 4.

Results of the direct hypothesized paths

CFI

RMSEA

$\begin{array}{lll}0.34^{* * *} & 0.18^{* *} & \text { Accept } \\ 0.30^{* * *} & 0.47^{* * *} & \text { Accept } \\ 0.12^{* *} & 0.14^{* *} & \text { Accept }\end{array}$

Note(s): $*, * *, * *=p<0.10, p<0.05$, and $p<0.001$, respectively. ns $=$ not significant

Figure 2.

Hypothesized model

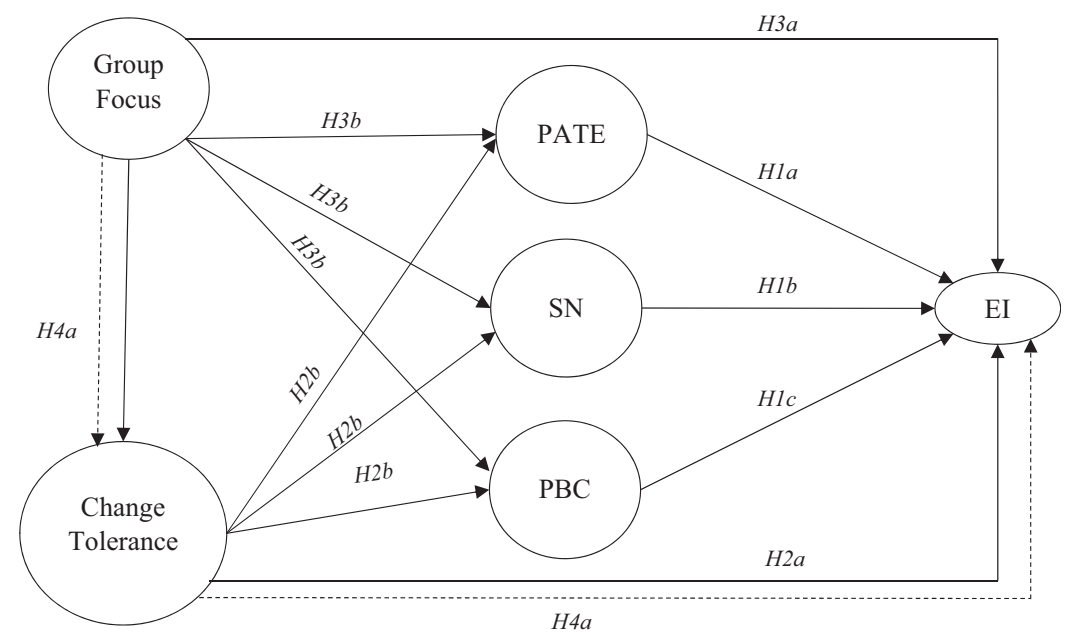

Hypothesis testing

The results for the significance of each proposed path/relationship were evaluated. For the sample of men, the three dimensions (PATE $=23 \%, \mathrm{SN}=11 \%, \mathrm{PBC}=17 \%$ ) and cultural indicators $(\mathrm{CT}=21 \%$ ) together explained $44 \%$ of the variance in EIs. For the sample of women, the three dimensions (PATE $=8 \%, \mathrm{SN}=2 \%, \mathrm{PBC}=10 \%$ ) and cultural indicators $(\mathrm{CT}=12 \%)$ together explained $44 \%$ of the variance in EIs. 
Concerning $H 1$, all three antecedents of TPB had a significant and positive impact on EIs for both men and women. The impact of PATE on EIs was stronger for men $\left(0.34^{* * * * *}\right)$ than for women $\left(0.18^{* * *}\right)$, supporting $\mathrm{HI}$. For SN and PBC, the impact was stronger in the case of women $\left(0.47^{* * * *}, 0.14^{* * *}\right)$ than in men $\left(0.30^{* * * *}, 0.12^{* * *}\right)$; thus, $H 1 b$ and $H 1 c$ were also supported.

Regarding $H 2$, which concerns the cultural variable of change tolerance, there was a significant and positive impact of CT on the TPB constructs (i.e. PATE, SN, PBC) for both men and women. However, the impact of CT on EIs was not significant for men but was positive and significant for women. $H 2 a$ was not supported as the path from CT to EIs in the case of men was not significant. However, $H 2 b$ was accepted as the paths were significant and stronger for men $\left(0.40^{* * * *}, 0.30^{* * *}, 0.32^{* * * *}\right)$ than for women $\left(0.27^{* * * *}\right.$, $\left.0.14^{* * *}, 0.27^{* * * *}\right)$.

$H 3$, which was in relation to the cultural variable group focus, revealed that the direct paths from GF to PATE, SN, and PBC for women were not significant, while for men, there was a significant and positive direct impact from GF to PATE and PBC. Further, the direct relationship between GF and EIs was insignificant for men and significant and negative for women. Thus, $H 3 a$ and $H 3 b$ were not supported.

\section{Mediating analysis}

To examine the mediating role of $\mathrm{CT}$ and TPB constructs in the relationship between $\mathrm{GF}$ and EIs, we examined several indirect paths using PROCESS macro version 3 (Hayes, 2018) and bootstrapping analysis with 5,000 sub-samples in AMOS. Tables 5 and 6 report the results for specific indirect effects for men and women, respectively. Indirect effects analysis was applied to test the type of mediation (Zhao et al., 2010). Zhao et al. (2010) identified five types of mediation effects: complementary, competitive, indirect only mediation, direct only non-mediation, and no effect non-mediation. Complementary and indirect only mediation are similar to Baron and Kenney's (1986) partial and full mediation, respectively. By examining the significance value of the direct path (see Table 4) and the role of the mediating variables, the variations and type of mediation can be detected between the two samples (see Tables 5 and 6). Where both the direct and indirect effects are significant, partial mediation is achieved. To determine the nature of partial mediation, the product of the direct and indirect effects was calculated; if the sign of the product is positive, then complementary partial mediation is achieved, otherwise, competitive partial mediation is achieved.

\begin{tabular}{|c|c|c|c|c|c|c|}
\hline Relationships & $\begin{array}{l}\text { Effect } \\
\text { size }\end{array}$ & $\mathrm{Sig} / \mathrm{ns}$ & $\begin{array}{l}\text { Lower } \\
\text { threshold }\end{array}$ & $\begin{array}{l}\text { Upper } \\
\text { threshold }\end{array}$ & Hypotheses & Mediation type \\
\hline $\mathrm{GF} \rightarrow \mathrm{PATE} \rightarrow \mathrm{EIs}$ & 0.042 & ns & -0.019 & 0.114 & $H 3 b$ & - \\
\hline $\mathrm{GF} \rightarrow \mathrm{SN} \rightarrow \mathrm{EIs}$ & -0.007 & ns & -0.044 & 0.023 & $H 3 b$ & - \\
\hline $\mathrm{GF} \rightarrow \mathrm{PBC} \rightarrow \mathrm{EIs}$ & 0.015 & ns & -0.004 & 0.054 & $H 3 b$ & - \\
\hline $\mathrm{GF} \rightarrow \mathrm{CT} \rightarrow \mathrm{EIs}$ & 0.045 & ns & -0.017 & 0.114 & $H 4 a$ & $\begin{array}{l}\text { No-effect } \\
\text { (non-mediation) }\end{array}$ \\
\hline $\mathrm{GF} \rightarrow \mathrm{CT} \rightarrow \mathrm{PATE}$ & 0.184 & Sig & 0.113 & 0.273 & - & Complementary \\
\hline $\mathrm{GF} \rightarrow \mathrm{CT} \rightarrow \mathrm{SN}$ & 0.135 & Sig & 0.067 & 0.219 & - & Indirect-only \\
\hline $\mathrm{GF} \rightarrow \mathrm{CT} \rightarrow \mathrm{PBC}$ & 0.145 & Sig & 0.076 & 0.225 & - & Complementary \\
\hline \multicolumn{7}{|l|}{ Multiple/serial mediation } \\
\hline $\mathrm{GF} \rightarrow \mathrm{CT} \rightarrow \mathrm{PATE} \rightarrow \mathrm{EIs}$ & 0.061 & Sig & 0.020 & 0.123 & $H 4 b$ & Indirect-only \\
\hline $\mathrm{GF} \rightarrow \mathrm{CT} \rightarrow \mathrm{SN} \rightarrow \mathrm{EIs}$ & -0.002 & ns & -0.019 & 0.012 & $H 4 b$ & No-effect \\
\hline $\mathrm{GF} \rightarrow \mathrm{CT} \rightarrow \mathrm{PBC} \rightarrow \mathrm{EIs}$ & 0.013 & ns & -0.002 & 0.033 & $H 4 b$ & No-effect \\
\hline
\end{tabular}

Culture and theory of planned behavior

(1)




\begin{tabular}{|c|c|c|c|c|c|c|c|}
\hline \multirow[b]{2}{*}{$\begin{array}{l}\text { EJMBE } \\
31,2\end{array}$} & \multirow[b]{2}{*}{ Relationships } & \multirow[b]{2}{*}{$\begin{array}{c}\text { Effect } \\
\text { size }\end{array}$} & \multirow[b]{2}{*}{$\mathrm{Sig} / \mathrm{ns}$} & \multirow[b]{2}{*}{$\begin{array}{c}\text { Lower } \\
\text { threshold }\end{array}$} & \multirow[b]{2}{*}{$\begin{array}{c}\text { Upper } \\
\text { threshold }\end{array}$} & & \\
\hline & & & & & & Hypotheses & $\begin{array}{l}\text { Mediation } \\
\text { type }\end{array}$ \\
\hline \multirow{7}{*}{202} & $\mathrm{GF} \rightarrow \mathrm{PATE} \rightarrow \mathrm{EIs}$ & 0.008 & ns & -0.021 & 0.049 & $H 3 b$ & - \\
\hline & $\mathrm{GF} \rightarrow \mathrm{SN} \rightarrow \mathrm{EIs}$ & -0.039 & ns & -0.101 & 0.018 & $H 3 b$ & - \\
\hline & $\mathrm{GF} \rightarrow \mathrm{PBC} \rightarrow \mathrm{EIs}$ & 0.012 & ns & -0.009 & 0.038 & $H 3 b$ & - \\
\hline & $\mathrm{GF} \rightarrow \mathrm{CT} \rightarrow \mathrm{EIs}$ & 0.036 & ns & -0.006 & 0.087 & $H 4 a$ & No-effect \\
\hline & $\mathrm{GF} \rightarrow \mathrm{CT} \rightarrow \mathrm{PATE}$ & 0.093 & Sig & 0.044 & 0.161 & - & Indirect-only \\
\hline & $\mathrm{GF} \rightarrow \mathrm{CT} \rightarrow \mathrm{SN}$ & 0.049 & Sig & 0.004 & 0.112 & - & Indirect-only \\
\hline & $\mathrm{GF} \rightarrow \mathrm{CT} \rightarrow \mathrm{PBC}$ & 0.092 & Sig & 0.043 & 0.160 & - & Indirect-only \\
\hline \multirow{5}{*}{$\begin{array}{l}\text { Table } 6 . \\
\text { Specific indirect } \\
\text { effects (Women) }\end{array}$} & Multiple mediation & & & & & & \\
\hline & $\mathrm{GF} \rightarrow \mathrm{CT} \rightarrow \mathrm{PATE} \rightarrow \mathrm{EIs}$ & 0.017 & Sig & 0.001 & 0.042 & $H 4 b$ & Competitive \\
\hline & $\mathrm{GF} \rightarrow \mathrm{CT} \rightarrow \mathrm{SN} \rightarrow \mathrm{EIs}$ & -0.007 & & -0.033 & 0.014 & $H 4 b$ & No-effect \\
\hline & $\mathrm{GF} \rightarrow \mathrm{CT} \rightarrow \mathrm{PBC} \rightarrow \mathrm{EIs}$ & 0.009 & Sig & 0.001 & 0.023 & $H 4 b$ & Competitive \\
\hline & \multicolumn{7}{|c|}{ Note(s): sig = significant; $\mathrm{ns}=$ not significant } \\
\hline
\end{tabular}

In the case of both men and women, $H 4 a$, which posited that CT mediates the relationship between GF and EIs, was not supported as the bootstrap confidence intervals included zero within the lower and upper threshold $\{$ men $=(-0.017,0.114)$; women $=(-0.006,0.087)\}$; thus, the indirect effect was not significant. For both men and women, the indirect effects of GF on TPB constructs through CT were significant and positive. For women, CT fully mediated the relationship between the GF and TPB constructs. GF explained EIs of women through the TPB. For men, following Zhao et al. (2010), the sign of the product of direct and indirect effects (in the case of PATE and PBC) was calculated. This was a case of complementary mediation, as the sign of the product was positive (Zhao et al., 2010). Thus, there was complementary partial mediation through CT in case of the impact from GF to PATE and PBC, and full mediation through CT for GF to SN. GF indirectly explained the EIs of men through the SN and both directly and indirectly through PATE and PBC.

$H 4 b$ concerned serial mediation in the mediating role of both $\mathrm{CT}$ and TPB constructs (PATE, SN, and PBC) between GF and EIs. First, the specific indirect effects through CT and each TPB construct (serial mediation) were evaluated (see Tables 5 and 6), and the total indirect effects (parallel mediation) were then examined between the two samples (see Table 7). For men, the direct effect of GF on EIs was not significant, although the specific indirect effects of GF on EIs through CT and PATE were significant and positive $(0.061$ $(0.020,0.123))$, thus confirming that CT and PATE together fully mediate the relationship between GF and EIs of men. However, for women, the direct effect of GF on EIs was significant and negative $\left(-0.19^{* * *}\right)$. Moreover, the specific indirect effects of GF on EIs through CT and PATE $(0.017(0.001,0.042))$ and CT and PBC $(0.009(0.001,0.023))$ were significant and positive, thus confirming the presence of competitive partial mediation.

Table 7.

Comparison between total indirect and direct effects

\begin{tabular}{|c|c|c|c|c|}
\hline Relationships & $\begin{array}{c}\text { Men } \\
\text { Effect size (Bootstrap CI/p } \\
\text { value) }\end{array}$ & $\mathrm{Sig} / \mathrm{ns}$ & $\begin{array}{c}\text { Women } \\
\text { Effect size (Bootstrap CI/p } \\
\text { value) }\end{array}$ & $\mathrm{Sig} / \mathrm{ns}$ \\
\hline $\begin{array}{l}\text { CT } \rightarrow \text { EIs (direct effect) } \\
\text { GF } \rightarrow \text { EIs (direct effect) } \\
\text { CT } \rightarrow \text { EIs (through TPB) } \\
\text { GF } \rightarrow \text { EIs (through CT }\end{array}$ & $\begin{array}{c}0.099(p=0.142) \\
-0.088(p=0.155) \\
0.262(0.165,0.367) \\
0.249(0.145,0.360)\end{array}$ & $\begin{array}{l}\text { ns } \\
\text { ns } \\
\text { Sig } \\
\text { Sig }\end{array}$ & $\begin{array}{c}0.107(p=0.063) \\
-0.190(p<0.001) \\
0.153(0.062,0.249) \\
0.087(-0.016,0.188)\end{array}$ & $\begin{array}{l}\text { Sig } \\
\text { Sig } \\
\text { Sig } \\
\text { Sig }\end{array}$ \\
\hline
\end{tabular}


The other specific indirect effects through CT and SN, and CT and PBC were not significant for men. Likewise, for women, the specific indirect effects through CT and SN on the relationship between $\mathrm{GF}$ and EIs were not significant.

The total indirect effects are the sum of all the specific indirect effects through all the mediators of the causal antecedent on the consequent variable (Hayes, 2018). A comparison between the direct effect of GF on EIs and CT on EIs and the total indirect effects through the mediators are illustrated in Table 7. To explain the EIs of men, both CT and GF indirectly explain more through PATE, SN and PBC. TPB constructs fully mediate the relationship between $\mathrm{CT}$ and EIs, and $\mathrm{CT}$ and TPB constructs fully mediate the relationship between GF and EIs in men. On the other hand, for women, adding TPB constructs as mediators enhanced the relationship between CT and EIs. Furthermore, CT and TPB constructs as mediators to explain the relationship between GF and EIs of women, had a significant and net positive effect.

\section{Discussion}

This study developed an integrative model using two cultural dimensions (CT and GF) and the TPB model to understand how these dimensions influence students' intentions toward entrepreneurship.

\section{Antecedents of intentions and gender}

The significant relationship between PATE and EIs for both genders, even if stronger for men, reveals that young women no longer feel that they are less qualified than men for entrepreneurial careers, thus breaking gender stereotypes, which traditionally associate entrepreneurship with masculinity traits (Stedham and Wieland, 2017). While there were inconsistencies in previous findings about SN (Moriano et al., 2012), the current study demonstrates the importance of this factor for both genders. The relationship between SN and EIs is stronger for women. This could be justified by the fact that women, more than men, tend to be strongly influenced by societal values and the roles ascribed to them (Haddad, 2017; Haddad and Loarne, 2015; Sweida and Sherman, 2020). Their social circle's positive view of entrepreneurship has an impact on their intentions. The link between PBC and EIs, which is positive and significant for male and female students, reiterates the importance of self-efficacy in explaining EIs (Elnadi and Gheith, 2021; Krueger et al., 2000; Santos et al., 2016). Consistent with Kickul et al. (2008), the current study revealed that the relationship is stronger for women. This could be explained by the fact that low self-efficacy is usually considered a major barrier to female entrepreneurship (Haddad et al., 2016). Women with high self-efficacy tend to adopt unconventional paths (Bandura, 1977) and show eagerness to undergo the entrepreneurial process.

\section{Change tolerance}

This study examined the impact of CT on TPB antecedents and EIs, either directly or through mediating effects. The findings reveal a direct and positive relationship between CT and EIs for women students and not for men. However, the mediation effect between CT and EIs through EIs antecedents (PATE, SN, PBC) was stronger for men. This implies that women students who are tolerant to change tend to have higher EIs than their male counterparts. These results align with previous research demonstrating that risk-tolerant women show a strong tendency toward entrepreneurial activities (Anlesinya, 2019; Gurel et al., 2021). One possible explanation of the findings on CT may stem from the French context of the study. In France, the role of women has been revolutionized and they have been encouraged to take initiatives and risks without fear of making mistakes or being rejected by their community. 
EJMBE 31,2
Furthermore, the current research illustrated the positive and significant impact of CT on TPB antecedents for both genders; however, it exerted a stronger influence on men than women. This finding confirms the fact that men, being more change-tolerant and less riskaverse than women, show higher entrepreneurial propensity (Yukongdi and Lopa, 2017), and have a higher self-efficacy level (Serino and Buccino, 2019). Moreover, women with high levels of CT culture feel less conditioned by societal influences and less sensitive to SN (Haddad et al., 2016).

\section{Group focus and the mediating effect of change tolerance}

The results reveal there is no direct link between GF and EIs for men; however, the relationship is negative and significant for women. This indicates that, in the men's sample, collective practices do not influence intentions toward entrepreneurship. In the women's sample, high-level GF leads to a low level of EIs. This contradicts the findings of Rantanen and Toikko (2017) and Lechler (2001) regarding the importance of collective practices in entrepreneurial development. The absence of an indirect effect between GF and EIs through TPB antecedents for both genders contradicts previous research (Farrukh et al., 2019; Hueso et al., 2020), which proved the mediating effect of SN between collectivism and EIs. A plausible reason for GF not positively and significantly impacting EIs, either directly or indirectly, could be the French environment itself. France is considered a developed country where people receive support from institutions such as the government, laws, and social programs. Students depend more on institutional rather than in-group collectivism to create new business ventures (Bullough et al., 2017). Another reason could be that students may hold both an independent and dependent sense of self, and each of these two dimensions may prevail across different contexts (Markus and Kitayama, 1991).

Another important finding is the multiple mediation effect of CT and TPB antecedents between GF and EIs. This finding holds for both genders, but it is higher for men, which could be explained by the dissimilar effect of contextual influences on the perceptions of both genders (Byrne and Fayolle, 2010). One possible explanation for the mediation effects could be the multicultural context of international business schools in France. Students from different nationalities interact together and mutually influence each other, which may lead them to be more open minded and more tolerant regarding innovation and change (Matthews et al., 2020; Shane, 1993). The shared cultural values among students may influence the extent to which they consider entrepreneurial behaviors as feasible and desirable, hence nurturing positive intentions toward entrepreneurship (Haddad et al., 2021; Krueger et al., 2013; Watson et al., 2019).

\section{Conclusion}

Entrepreneurship is one of the primary drivers of economic growth; thus, it is essential to gain better insights into the factors that affect its development. To the best of our knowledge, no study has compared and contrasted gender differences in relation to the direct and indirect role of CT and GF in predicting EIs among business students. Thus, this study contributes to the literature on culture, gender, and entrepreneurship by developing an extended framework of TPB that integrates individual cultural dimensions and establishes comparisons between men and women.

\section{Research implications}

The theoretical implications of this study are threefold. The first is that national cultural dimensions fall short of explaining/predicting EIs in a diverse context, such as international business schools. Future research should focus more on the context, on multiculturalism, on 
the individual dimensions, and the way they impact EIs. The second implication is that it explains the controversial findings about collective values and practices by revealing that, on their own, they fail to drive positive intentions toward entrepreneurship unless they occur in a culture that is open minded and tolerant to novelty, risk, and change. The third implication relates to gender differences. The study aligns with previous research, thus showing that men are more tolerant to change than women. However, women who are tolerant to change have higher EIs than their male counterparts and feel less conditioned by societal influences and SN.

This study has practical implications for business schools. It informs education managers about the need to create an environment that encourages diversity and fosters free thinking, risk taking, mistake-driven learning, and tolerance to change. Academics can work on implementing shared cultural values and beliefs regarding the importance of entrepreneurship and the increasingly growing role of women as major players in economic growth. Moreover, business schools could create an entrepreneurial environment with appropriate institutional infrastructure and culture that encourages and strengthens students' self-efficacy and ambition to become entrepreneurs. Thus, it is suggested that they provide entrepreneurship modules in their curricula to increase students' EIs. Entrepreneurial education needs to be based on practical actions and peer-to-peer learning that capitalizes on collective practices in a change-tolerant culture to reduce risk aversion and produce positive intentions toward entrepreneurship. Business schools could encourage the creation of culturally diverse teams where learners work collaboratively and try out a variety of new ideas. Taking actions among learners' diverse teams where mistakes are allowed increases creativity and self-efficacy, encourages risk taking, and enhances students' EIs.

\section{Limitations and future directions for research}

This study has some limitations. It was conducted in one country; it is recommended that the model be tested across different contexts. This research did not consider the biculturalism factor and did not conduct a comparative analysis that considers French students versus international students living in France. Future research may benefit from using nationality to control for such variances. This study emphasizes two cultural dimensions and future work may consider the integration of other dimensions to analyze their impact on the outcomes of this study.

\section{References}

Ajzen, I. (1991), "Theory of planned behavior", Organizational Behavior and Human Decision Processes, Vol. 50 No. 2, pp. 179-211, doi: 10.1016/0749-5978(91)90020-T.

Anderson, J.C. and Gerbing, D.W. (1988), "Structural equation modeling in practice: a review and recommended two-step approach", Psychological Bulletin, Vol. 103 No. 3, pp. 411-423, doi: 10. 1037/0033-2909.103.3.411.

Anlesinya, A., Adepoju, O.A. and Richter, U.H. (2019), "Cultural orientation, perceived support, and participation of female students in formal entrepreneurship in the sub-Saharan economy of Ghana”, International Journal of Gender and Entrepreneurship, Vol. 11 No. 3, pp. 299-322, doi: 10.1108/IJGE-01-2019-0018.

Bandura, A. (1977), "Self-efficacy: towards a unifying theory of behavioral change", Psychological Review, Vol. 84 No. 2, pp. 191-215, doi: 10.1037//0033-295x.84.2.191.

Baron, R.M. and Kenny, D.A. (1986), "Moderator-mediator variable distinction in social psychological research: conceptual, strategic, and statistical considerations", Journal of Personality and Social Psychology, Vol. 51 No. 6, pp. 1173-1182, doi: 10.1037//0022-3514.51.6.1173.
Culture and theory of planned behavior 
EJMBE 31,2

Bogatyreva, K., Edelman, L.F., Manolova, T.S., Osiyevskyy, O. and Shirokova, G. (2019), "When do entrepreneurial intentions lead to actions? The Role of National Culture", Journal of Business Research, Vol. 96, pp. 309-321.

Boubker, O., Arroud, M. and Ouajdouni, A. (2021), "Entrepreneurship education versus management students' entrepreneurial intentions. A PLS-SEM approach", International Journal of Management Education, Vol. 19 No. 1, doi: 10.1016/j.jme.2020.100450,100450.

Bullough, A., Renko, M. and Abdelzaher, D. (2017), "Women's business ownership: operating within the context of institutional and in-group collectivism", Journal of Management, Vol. 43 No. 7 , pp. 2037-2064, doi: 10.1177/0149206314561302.

Busenitz, L.W., Gomez, C. and Spencer, J.W. (2000), "Country institutional profiles: unlocking entrepreneurial phenomena”, Academy of Management Journal, Vol. 43 No. 5, pp. 994-1003.

Byrne, J. and Fayolle, A. (2010), "A feminist inquiry into entrepreneurship training”, Theory and Practice of Entrepreneurship, pp. 76-100.

Choukir, J., Aloulou, W.J., Ayadi, F. and Mseddi, S. (2019), "Influences of role models and gender on Saudi Arabian freshman students' entrepreneurial intention”, International Journal of Gender and Entrepreneurship, Vol. 11 No. 2, pp. 186-206.

De Jorge-Moreno, J., Castillo, L. and Triguero, M. (2012), "The effect of business and economics education programs on students' entrepreneurial intentions", European Journal of Training and Development, Vol. 36 No. 4, pp. 409-425, doi: 10.1108/03090591211220339.

Díaz-García, M.C. and Jiménez-Moreno, J. (2010), "Entrepreneurial intention: the role of gender", International Entrepreneurship and Management Journal, Vol. 6 No. 3, pp. 261-283, doi: 10.1007/ s11365-008-0103-2.

Doran, J., McCarthy, N. and O'Connor, M. (2018), "The role of entrepreneurship in stimulating economic growth in developed and developing countries", Cogent Economics and Finance, Vol. 6 No. 1, doi: 10.1080/23322039.2018.1442093,1442093.

Elnadi, M. and Gheith, M.H. (2021), "Entrepreneurial ecosystem, entrepreneurial self-efficacy, and entrepreneurial intention in higher education: evidence from Saudi Arabia”, International Journal of Management Education, Vol. 19 No. 1, doi: 10.1016/j.ijme.2021.100458,100458.

Farrukh, M., Lee, J.W.C., Sajid, M. and Waheed, A. (2019), "Entrepreneurial intention", Education + Training, Vol. 61 Nos 7/8, pp. 984-1000, doi: 10.1108/ET-09-2018-0194.

Fornell, C. and Larcker, D.F. (1981), "Evaluating structural equation models with unobservable variables and measurement errors", Journal of Marketing Research, Vol. 18 No. 1, pp. 39-50, doi: $10.1177 / 002224378101800104$.

García-Rodríguez, F.J., Gil-Soto, E., Ruiz-Rosa, I. and Sene, P.M. (2015), "Entrepreneurial intentions in diverse development contexts: a cross-cultural comparison between Senegal and Spain”, International Entrepreneurship and Management Journal, Vol. 11 No. 3, pp. 511-527, doi: 10. 1007/s11365-013-0291-2.

Gurel, E., Madanoglu, M. and Altinay, L. (2021), “Gender, risk-taking, and entrepreneurial intentions: assessing the impact of higher education longitudinally", Education + Training, Vol. 63 No. 5, pp. 777-792, doi: 10.1108/ET-08-2019-0190.

Haddad, G. (2017), “Understanding women entrepreneurial motivations: does age matter?", Lebanon: Social, Political, and Economic Issues, pp. 65-84.

Haddad, G. and Loarne, S.L. (2015), "Social networking and gender effects on opportunity identification", International Journal of Entrepreneurship and Small Business, Vol. 24 No. 1, pp. 23-40, doi: 10.1504/IJESB.2015.066155.

Haddad, G., Esposito, M. and Tse, T. (2016), "The social cluster of gender, agency, and entrepreneurship", International Journal of Entrepreneurship and Small Business, Vol. 28 No. 4, pp. 431-450, doi: 10.1504/IJESB.2016.077572. 
Haddad, G., Haddad, G. and Nagpal, G. (2021), "Can students' perceptions of the diverse learning environment affect their intentions toward entrepreneurship?", Journal of Innovation and Knowledge, Vol. 6 No. 3, pp. 167-176, doi: 10.1016/j.jik.2021.04.002.

Hair, J.F., Black, W.C., Babin, B.J., Anderson, R.E. and Tatham, R.L. (2014), Pearson New International Edition. Multivariate Data Analysis, 7th ed., Pearson Education Limited Harlow, Essex.

Culture and theory of planned behavior

Hayes, A.F. (2018), Introduction to Mediation, Moderation, and Conditional Process Analysis: A Regression-Based Approach, The Guilford Press, New York, NY.

Hayton, J.C., George, G. and Zahra, S.A. (2002), "National culture and entrepreneurship: a review of behavioral research", Entrepreneurship Theory and Practice, Vol. 26 No. 4, pp. 33-52, doi: 10. 1177/104225870202600403.

Hofstede, G. (1980), Culture Consequences: International Differences in Work-Related Values, Sage Publications, Beverly Hills, California, CA.

Hofstede, G. (2001), Culture Consequences: Comparing Values, Behaviors, Institutions, and Organizations across Nations, Sage Publications, Beverly Hills, California, CA.

Hueso, J.A., Jaén, I., Liñán, F. and Basuki, W. (2020), "Influence of collectivistic personal values on the formation of entrepreneurial intentions", International Small Business Journal: Researching Entrepreneurship, Vol. 38 No. 5, pp. 449-473, doi: 10.1177/0266242620903007.

Karimi, S., Biemans, H.J.A., Lans, T., Chizari, M., Mulder, M. and Mahdei, K.N. (2013), "Understanding role models and gender influences entrepreneurial intentions among college students", Procedia - Social and Behavioral Sciences, Vol. 93, pp. 204-214, doi: 10.1016/j.sbspro.2013.09.179.

Karimi, S., Biemans, J.A., Lans, T., Chizari, M. and Mulder, M. (2014), "Effects of role models and gender on students' entrepreneurial intentions", European Journal of Training and Development, Vol. 38 No. 8, pp. 694-727, doi: 10.1108/EJTD-03-2013-0036.

Kickul, J., Wilson, F., Marlino, D. and Barbosa, S.D. (2008), "Are misalignments of perceptions and selfefficacy causing gender gaps in entrepreneurial intentions among our nation's teens?”, Journal of Small Business and Enterprise Development, Vol. 15 No. 2, pp. 321-335.

Kirkley, W.W. (2016), "Entrepreneurial behavior: the role of values", International Journal of Entrepreneurial Behavior and Research, Vol. 22 No. 3, pp. 290-328, doi: 10.1108/IJEBR-022015-0042.

Kreiser, P.M., Marino, L.D., Dickson, P. and Weaver, K.M. (2010), "Cultural influences on entrepreneurial orientation: the impact of national culture on risk-taking and proactiveness in SMEs", Entrepreneurship Theory and Practice, Vol. 34 No. 5, p. 959984, doi: 10.1111/j.15406520.2010.00396.x.

Krueger, N.F. (2017), "Entrepreneurial intentions are dead: long-lived entrepreneurial intentions", International Studies in Entrepreneurship, Springer, Cham, pp. 13-34, doi: 10.1007/978-3-31945544-0_2.

Krueger, N.F. Jr, Reilly, M.D. and Carsrud, A.L. (2000), "Competing models of entrepreneurial intentions", Journal of Business Venturing, Vol. 15 Nos 5-6, pp. 411-432, doi: 10.1016/S08839026(98)00033-0.

Krueger, N., Liñán, F. and Nabi, G. (2013), “Cultural values and entrepreneurship”, Entrepreneurship and Regional Development, Vol. 25 Nos 9-10, pp. 703-707, doi: 10.1080/08985626.2013.862961.

Lechler, T. (2001), "Social interaction: a determinant of entrepreneurial team venture success", Small Business Economics, Vol. 16 No. 4, pp. 263-278, doi: 10.1023/A:1011167519304.

Liñán, F. and Chen, Y.W. (2009), "Development and cross-cultural application of a specific instrument to measure", Entrepreneurial Intentions Entrepreneurship Theory and Practice, Vol. 33 No. 3, pp. 593-617, doi: 10.1111/j.1540-6520.2009.00318.x.

Linan, F., Urbano, D. and Guerrero, M. (2011), "Regional variations in entrepreneurial cognition: startup intentions of university students in Spain", Entrepreneurship and Regional Development, Vol. 23 Nos 3/4, pp. 187-215. 
EJMBE 31,2

Lortie, J. and Castogiovanni, G. (2015), "The theory of planned behavior in entrepreneurship research: what we know and future directions", International Entrepreneurship and Management Journal, Vol. 11 No. 4, pp. 935-957, doi: 10.1007/s11365-015-0358-3.

Lu, G., Song, Y. and Pan, B. (2021), "How university entrepreneurship support affects college students' entrepreneurial intentions: an empirical analysis from China", Sustainability, Vol. 13 No. 6, p. 3224, doi: 10.3390/su13063224.

Markus, H.R. and Kitayama, S. (1991), "Culture and the self: implications for cognition, emotion, and motivation”, Psychological Review, Vol. 98 No. 2, pp. 224-253, doi: 10.1037/0033-295X.98.2.224.

Matthews, B., Daigle, J. and Cooper, J. (2020), "Causative effects of motivation to transfer learning among relational dyads: the test of a model", European Journal of Management and Business Economics, Vol. 29 No. 3, pp. 297-314, doi: 10.1108/EJMBE-07-2019-0120.

McGrath, R.G., MacMillan, I.C. and Scheinberg, S. (1992), "Elitists, risk-takers, and rugged individualists? An exploratory analysis of cultural differences between entrepreneurs and non-entrepreneurs", Journal of Business Venturing, Vol. 7 No. 2, pp. 115-135, doi: 10.1016/08839026(92)90008-F.

Moriano, J.A., Gorgievski, M., Laguna, M., Stephan, U. and Zarafshani, K. (2012), "A cross-cultural approach to understanding entrepreneurial intention”, Journal of Career Development, Vol. 39 No. 2, pp. 162-185.

Morris, M.H., Davis, D.L. and Allen, J.W. (1994), "Fostering corporate entrepreneurship: cross-cultural comparisons of the importance of individualism versus collectivism", Journal of International Business Studies, Vol. 25 No. 1, pp. 65-89, doi: 10.1057/palgrave.jibs.8490849.

Mueller, S.L. and Thomas, A.S. (2001), "Culture and entrepreneurial potential”, Journal of Business Venturing, Vol. 16 No. 1, pp. 51-75, doi: 10.1016/S0883-9026(99)00039-7.

Nasip, S., Amirul, S.R., Sondoh, S.L. Jr and Tanakinjal, G.H. (2017), "Psychological characteristics and entrepreneurial intention”, Education + Training, Vol. 59 Nos 7/8, pp. 825-840, doi: 10.1108/ET10-2015-0092.

Nowiński, W. and Haddoud, M.Y. (2019), "The role of inspiring role models in enhancing entrepreneurial intention”, Journal of Business Research, Vol. 96, pp. 183-193, doi: 10.1016/j. jbusres.2018.11.005.

Oyserman, D. (2006), "High power, low power, and equality: culture beyond individualism and collectivism", Journal of Consumer Psychology, Vol. 16 No. 4, pp. 352-356, doi: 10.1207/ s15327663jcp1604_6.

Pruett, M., Shinnar, R., Toney, B., Llopis, F. and Fox, J. (2009), "Explaining entrepreneurial intentions of university students: a cross-cultural study", International Journal of Entrepreneurial Behavior and Research, Vol. 15 No. 6, pp. 571-594, doi: 10.1108/13552550910995443.

Rantanen, T. and Toikko, T. (2017), "The relationship between individualism and entrepreneurial intention - a Finnish perspective", Journal of Enterprising Communities: People and Places in the Global Economy, Vol. 11 No. 2, pp. 289-306, doi: 10.1108/JEC-10-2014-0021.

Rico, P. and Cabrer-Borrás, B. (2019), "Entrepreneurship, firms creation and regional performance", European Journal of Management and Business Economics, Vol. 28 No. 2, pp. 158-173, doi: 10. 1108/EJMBE-07-2018-0077.

Santos, F.J., Roomi, M.A. and Liñán, F. (2016), “About gender differences and the social environment in the development of entrepreneurial intentions", Journal of Small Business Management, Vol. 54 No. 1, pp. 49-66, doi: 10.1111/jsbm.12129.

Serino, L. and Buccino, G. (2019), "Entrepreneurial intentions among Italian students: the role of gender", International Journal of Academic Research in Business and Social Sciences, Vol. 9 No. 3, doi: 10.6007/IJARBSS/v9-i3/5801.

Seyoum, B., Chinta, R. and Mujtaba, B.G. (2021), "Social support as a driver of social entrepreneurial intentions: the moderating roles of entrepreneurial education and proximity to the US small 
business administration", Journal of Small Business and Enterprise Development, Vol. 28 No. 3, pp. 337-359, doi: 10.1108/JSBED-08-2020-0306.

Shane, S. (1993), "Cultural influences on national rates of innovation”, Journal of Business Venturing, Vol. 8 No. 1, pp. 59-73, doi: 10.1016/0883-9026(93)90011-S.

Shinnar, R.S., Giacomin, O. and Janssen, F. (2012), "Entrepreneurial perceptions and intentions: the role of gender and culture", Entrepreneurship Theory and Practice, Vol. 36 No. 3, pp. 465-493, doi: 10.1111/j.1540-6520.2012.00509.x.

Shinnar, R.S., Hsu, D.K., Powell, B.C. and Zhou, H. (2018), "Entrepreneurial intentions and start-ups: are women or men more likely to enact their intentions?", International Small Business Journal: Researching Entrepreneurship, Vol. 36 No. 1, pp. 60-80, doi: 10.1177/ 0266242617704277.

Solomon, C.M. and Schell, M.S. (2009), Managing across Cultures, McGraw-Hill Education, Tata.

Stedham, Y. and Wieland, A. (2017), "Culture, benevolent and hostile sexism, and entrepreneurial intentions", International Journal of Entrepreneurial Behavior and Research, Vol. 23 No. 4, pp. 673-687, doi: 10.1108/IJEBR-03-2016-0095.

Sweida, G. and Sherman, C.L. (2020), "Does happiness launch more businesses? Affect, gender, and entrepreneurial intention", International Journal of Environmental Research and Public Health, Vol. 17 No. 18, p. 6908, doi: 10.3390/ijerph17186908.

Watson, A., Dada, O., Wright, O. and Perrigot, R. (2019), "Entrepreneurial orientation rhetoric in franchise organizations: the impact of national culture”, Entrepreneurship Theory and Practice, Vol. 43 No. 4, pp. 751-772, doi: 10.1177/1042258717738519.

World Economic Forum (2020), "Unleashing the power of Europe's women entrepreneurs: six ideas to drive big change", available at: http://www3.weforum.org/.

Yordanova, D.I. and Tarrazon, M.A. (2010), “Gender differences in entrepreneurial intentions: evidence from Bulgaria”, Journal of Developmental Entrepreneurship, Vol. 15 No. 3, pp. 245-261, doi: 10. 1142/S1084946710001543.

Yukongdi, V. and Lopa, N.Z. (2017), "Entrepreneurial intention: a study of individual, situational and gender differences", Journal of Small Business and Enterprise Development, Vol. 24 No. 2, pp. 333-352, doi: 10.1108/JSBED-10-2016-0168.

Zhao, X., Lynch, J.G. Jr and Chen, Q. (2010), "Reconsidering baron and Kenny: myths and truths about mediation analysis", Journal of Consumer Research, Vol. 37 No. 2, pp. 197-206, doi: 10.1086/651257.

\section{Corresponding author}

Gloria Haddad can be contacted at: gloria.haddad@usj.edu.lb
Culture and theory of planned behavior 